\title{
“GEOHeritage" - GIS BASED APPLICATION FOR MOVABLE HERITAGE
}

\author{
Albina MOSCICKA \\ Institute of Geodesy and Cartography, Cartography Department \\ 27, Modzelewskiego Str., 02-679 Warsaw, Poland \\ albina.moscicka@igik.edu.pl
}

Keywords: digital heritage, web GIS, archives, public access, on-line map

\begin{abstract}
The paper will present the results of a research project „A methodology for mapping movable heritage”. This project, financed by the Polish Ministry of Science and Higher Education in 2008-2010, was realized by the Institute of Geodesy and Cartography in cooperation with the Research and Academic Computer Network (portal Polska.pl), the Central Archives of Historical Records and Department of Art History of the Wroclaw University. The idea of the project was to simplify access to digital movable cultural heritage by the use of spatial information. The main aspect of the project was to use a Geographic Information System (GIS) - as a technology and as a tool - to integrate different digital collections, present their content in one space and provide online access to them from one common level - from an online map. The essence of the research was to present on the online map movable monument as multi-spatial object. The base of this assumption is that most of monuments, especially movable ones, can have several places in the geographical space that are connected with them (several various space relations). As a rule archival documents were created in one place, describe the other, today can be kept in places far a way from the place they were prepared, and what more the parts of the same collection can be kept in different archives. Moreover, one single document can be connected or have relations (typological, thematically, temporal, spatial) with other relations to the same or the other one. The reason for it is that documents concerning various places are housed in the same archive, various documents can present the same place or the place of creating particular document can be the place of housing another. In the project the basic source material was digital collections of original records. Their metadata defined in the international standards of monuments' description were used for connecting digital monuments with the geographic space. With the use of these standards, the Internet application for presenting cultural heritage on the map was developed. It can be found at www.GEOHeritage.polska.pl (Polish version) and www.GEOHeritage.poland.pl (English version). The application is based on the Geographic Information System (GIS), and its functionality is mainly the elements of selecting the resources, presenting the documents on the map in different ways and finding their images. The paper will present methodological solutions necessary for building on-line map of movable heritage together with the functionality of the application.
\end{abstract}

\section{OBJECTIVES}

Movable monuments are these part of the heritage, which has no simple relation to the geographic space. Immovable monuments (churches, palaces, castles etc.) have unchangeable geographical localisation - they are located in one precisely defined place in the space: in some city/village, on some street etc. Accuracy of determination of this localisation depends only on our needs. Movable monuments (archival maps, manuscripts, old prints, works of art etc.) are the monuments that are not related to one place in the space - they can be easily moved from one place to another, so their relation to the geographic space can be changeable in time. Most of the movable monuments are created in one place, in the past they could be kept in different places, and now are stored in other place (archive, museum or library). What more, such monument, e.g. a written document (manuscript, old print) can refer to other places in geographical space (it can describe different places). Such situation is especially common on the territory of Europe - because of their rich history and related to this people migration, borders changes, exportation of cultural goods etc. What more, it is difficult (in most cases it is impossible at all) to know these localisations with the same accuracy as in case of immovable monuments. The starting point of the research was that Polish archives are spread all over Poland and also all over the world. As a rule archival documents were created in one place, describe the other, and today can be kept in places far away from the place they were prepared. What more, the parts of the same collection can be kept in different archives. Complicated Polish history caused that it is necessary to look, e.g. for the plan of Wieliczka (near Krakow) in Gdansk (more than $500 \mathrm{~km}$ north of Krakow), and the plan of Zabludow (near Bialystok) at the Warsaw University of Technology (more than $200 \mathrm{~km}$ west of Bialystok). A lot of Polish cultural goods can be find in other countries. In connection with it the authors have made an attempt to work out the idea of geovisualization information on movable monuments (Moscicka and Marzec, 2008a, 2008b). The main task was to develop the system of geographical 
information (GIS) on movable historical monuments and visualization of data gathered in it on the on-line map in the way that allows searching and finding movable monuments using geographical information. Crucial element of new presentation was also a timeline, integrated with the application that allows selecting historic and artistic periods, and defining the time period of our search. The task was complicated because so far this kind of research has not been undertaken. There are neither Polish nor international sources that describe this problem and the way of its implementation. The functionality of the on-line map was developed on the basis of the results of the research of Internet users' needs and consultations with experts. The main aim was to meet users' expectations. Further research of their needs that will help us to define the directions of application development; it will be conducted on larger scale, using the pilot application.

\section{METHODOLOGY}

The essence of the research is to present on the on-line map a movable monument as multi-spatial object (Fig. 1). The basis of this assumption is that most of monuments, especially movable ones, can have several places in the geographical space that are connected with them (several various space relationships). In our research we define "place" as a city or village, because in the most cases, there is no possible to determine more precisely e.g. place of creation.

These places can be:

- the place where the monument was created;

- the place or places where the monument was housed in the past;

- the place where the monument is kept recently;

- the place or places connected with the monument thematically - in case of maps it is a part of space presented on them.

Moreover, one single document can be connected or have relationship (typological, thematically, temporal, spatial) with other document. The reason for it is that documents concerning various places are housed in the same archive, various documents can present the same place or the place of creating particular document can be the place of housing another. In the project the basic source material was digital collections of original records. These high quality scans were the material to prepare electronic documents presenting monuments called the digital copy of the monuments.

Moreover, one single document can be connected or have relationship (typological, thematically, temporal, spatial) with other document. The reason for it is that documents concerning various places are housed in the same archive, various documents can present the same place or the place of creating particular document can be the place of housing another. In the project the basic source material was digital collections of original records. These high quality scans were the material to prepare electronic documents presenting monuments called the digital copy of the monuments.

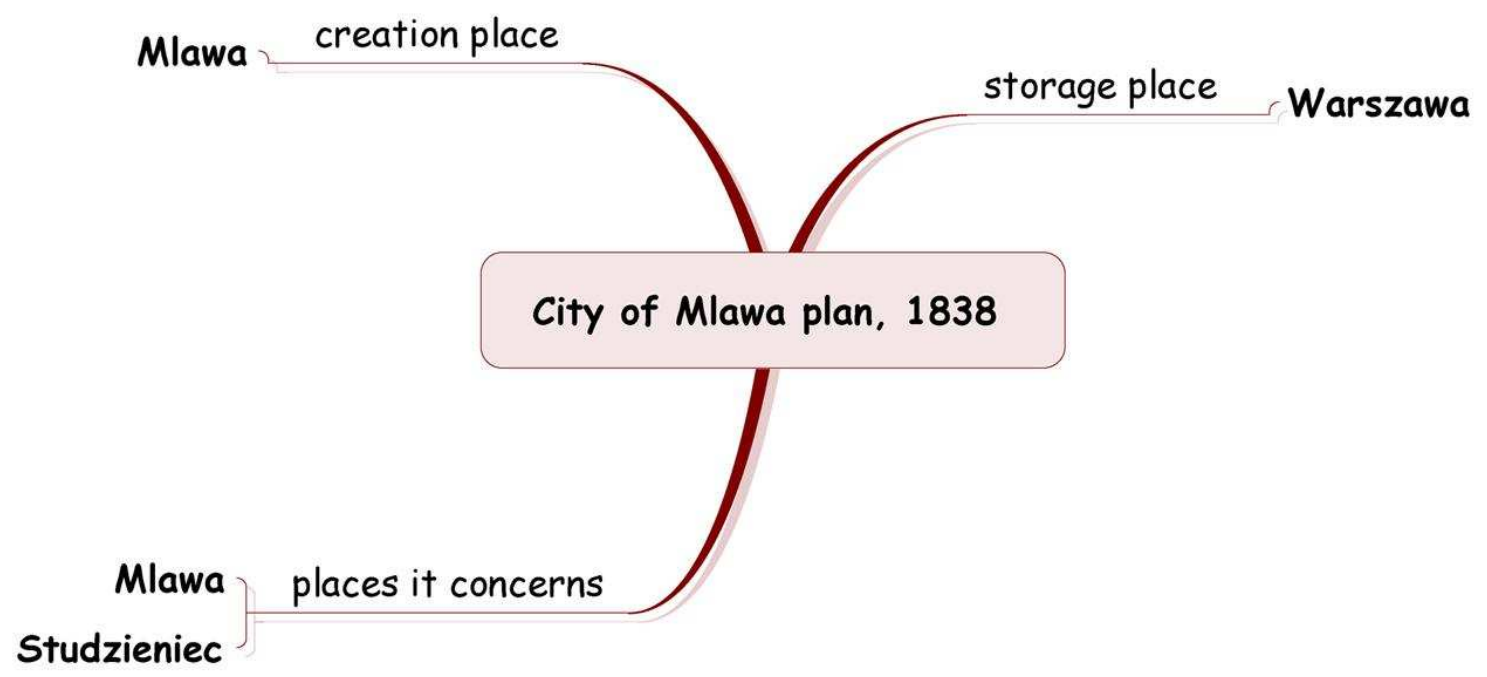

Figure 1: Multi-spatial object - few space relations of one monument

As a source data in the project digital copies of the movable monuments were used. The digital copies of the monuments are described by means of metadata that facilitates searching, controlling, understanding and managing them (Ordinance, 2006). The metadata are defined in the international standards of monuments' description. It describes 
which elements can or should be used in the electronic description of the copy of the monument to get basic characteristics of the monument and meet requirements for electronic documents. Moreover, such descriptions are used by archivists or historians, so they are understandable for all - data deliverers, GIS creator and the final users. In the project, the digital copies of the movable monuments together with their metadata prepared in the international standards for monument description were used. These standards, beside basic information identifying a monument, contain also data that enables to link it with the geographical space. Moreover, they also contain data which allow to define relations between objects. As the source collections two types of resources were used:

- part of collection "Cities in archival documents", presented so far in the portal Polska.pl; more than 100 written documents, described in xml files in the EAD standard (Meissner, 2002; URL; Wajs, 2000, 2003) were prepared;

- works of art from the church in Zorawina (Dolnoslaskie Voivodship); almost 100 works of art, described in xml files in the ObjectID standard were prepared.

As the background cartographic data digital map of Poland in scale 1:200 000, developed at the Institute of Geodesy and Cartography, Warsaw, was used. Together with the descriptions of the above monuments, dictionary of historical and artistic periods, types of monuments, institutions and people were created. There was also prepared the dictionary of geographic places connected with the monuments. In this dictionary, connections with the places used in monuments descriptions and coordinates of these places were defined. Coordinates were determined in the coordinate system of the digital map of Poland applied. Use of dictionaries allows to connect monuments with the geographic space and, consequently, to build geographic information system about movable heritage. With the use of standards of describing the monuments, the pilot Internet application for presenting cultural heritage on the map was developed. It is based on the GIS, and its functionality is mainly the elements of selecting the resources, presenting the documents on the map in different ways and finding their images. The result of the research is the solution for presenting in one common surface - in one application - not only information about places connected with the movable monuments, but also their images. Monuments are presented in such way that enables studying historical objects in comparable degree as during the visit in archives (Wajs and Marzec, 2009).

\section{RESULTS}

The result of the project discussed is a web application for the presentation of the heritage on the map. It is accessible in the Internet at the www.GEOHeritage.polska.pl (Polish version) and www.GEOHeritage.poland.pl (English version). The start page of the application is presented in Figure 2.

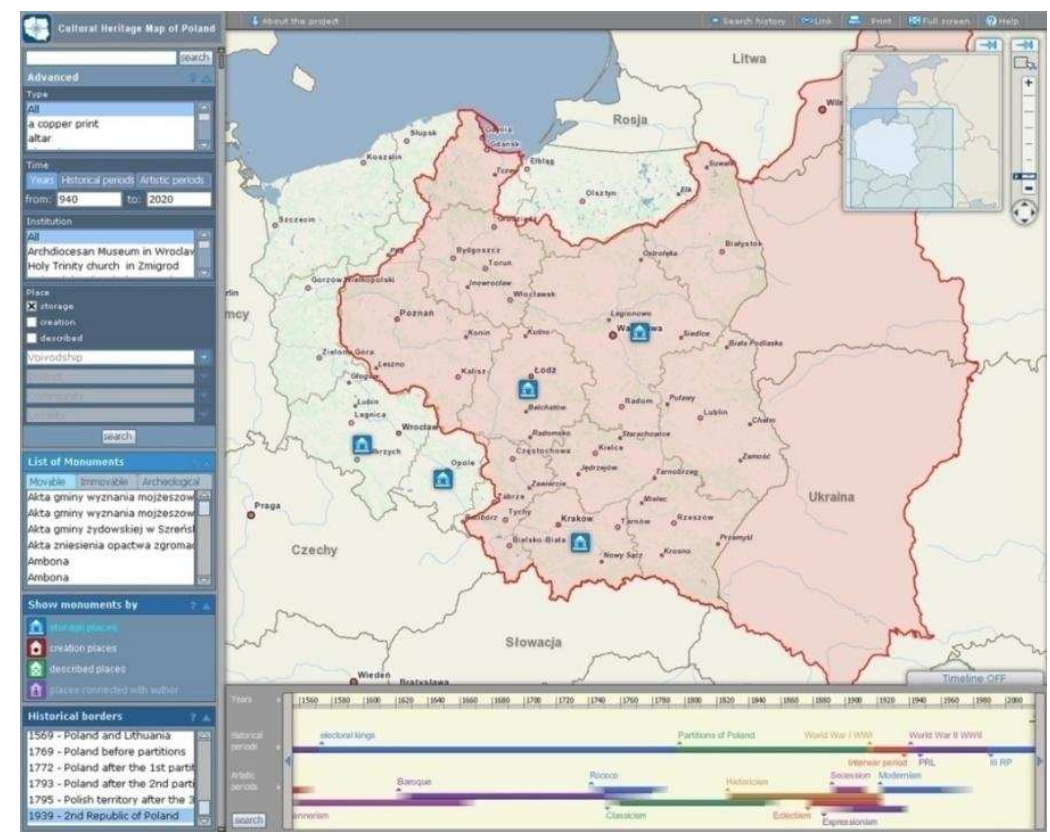

Figure 2: Start page of the "GEOHeritage" application 
The elements of selecting the resources, presenting the documents on the map in different ways as well as finding their descriptions and images reflect the main functionality of the application. The major parts of the application developed are:

- the main window - map window, where monuments are presented, together with the tools necessary for zooming and moving map;

- the top menu with the additional tools as history of presented maps, link to the present map view and icon for printing them, and - very useful - full screen option;

- interactive timeline, based on time of creation resources presented on the map;

- the left menu with the main tools for searching and presenting thematic data.

In the left menu, first of all, there are located tools for selecting the resources. Searching the resources is possible at two levels. Easy search contains text searching of all elements of monument description based on entered word, i.e. searching in the name or comments on the monument. Advanced search contains both: elements of easy search and also gives possibility to extend the selection criteria - to the type of the monuments, dates or creation period, institution of storing, and also to selection of geographic criteria. Resources can be searched by dates or period of creation. There are two types of periods: historical periods - based on Polish historical events, and artistic periods - based on styles in art. Moreover, this search is linked with the timeline. By choosing a period from the list or by entering the dates in the menu, one automatically changes the timeline settings. This feature works both ways: timeline is interactive and is divided into years, historical and artistic periods. It is possible to choose historical or artistic period by clicking in a colourful line that symbolizes exact period, as far as moving arrows pointing years on the time scale. Any change on timeline, as far as using search menu, results in reducing or extending the amount of monuments presented on the map. Searching using geographic criteria is possible by choosing name of a place and also by choosing an administrative unit (on different level). What is more important, it is possible to select what kind of places we would like to find: place of creation, storage place or places which are connected with the document topic. Below the search tool list of monuments is located. It is a list of all objects currently presented on the map. The resource presented on the map can be enriched by choosing the view with historical borders of Poland and visualize the historical context of creation or storage the resource in the selected period. Below the list of monuments, one of the most important tool - a tool for changing thematic content of the map, is located. It was assumed that the way of presentation resources on the map depends on users' needs or interests. So, the tool for changing aspect of presentation resources, which allows to show monuments by: creation places, described places and storage places is provided. Each of them works as a separate independent thematic layer. What is the most important, each of them is based on the same set of monuments but present them in different spatial aspect. It is possible to move between layers and change the aspect of presentation on the map of the same set of monuments in any time. The functionality of the application is also connected with the interactivity of the map. The icons that appear on the map and symbolize the places connected with the monuments are active. When the user move a mouse cursor on them - the number of monuments in chosen place will be shown, together with the name of place or administrative unit to which resources symbolized by the icon are related. When the user clicks on the icon, the menu with the additional options related to changing thematic map content or aspect of resources presentation, will be shown. There is an option which shows all (or selected) monuments created in pointed place. If this option was chosen, the list of chosen monuments will be presented in a new window. These chosen monuments are listed in a new window and they can be presented on the map as the new collection - in such case monuments' list will be replaced with the selected monuments' list and new collection will be presented on the map. If one object from the list was selected, its image and its description will be shown in a new window. Functionality presented so far is related to a set of monuments. In the application there are also solutions for the presentation of spatial information about one single object. By choosing one object from the list of monuments all places connected with that monument - the place of its creation, its storage place and - if they appear - places concerning its topic - are presented on the map. In some cases there is possible to present on the map additional spatial information about topics connected with the presented objects, i.e. places of activity of this monument's author. As in the case of presentation monuments' collections, the icons presenting spatial information about one single object are also active. When the user clicks on them he/she will see menu from which the other options can be chosen. There are the same options as in case of icons representing a set of monuments, as well as, e.g. possibility of selecting monuments connected with the chosen one (i.e. monuments from the same collection). From this one single object icons' menu the users can also go to monument description and to its image. Because monuments described with the use of international standards were used as the source data for monuments description, the scope of the information about each object is the same as in the standard (EAD or Object ID). The way of image presentation was one of the most important aspects in the project. The authors assumed that the user should be able to study archival documents in comparable degree as during the visit in archives. Thus, Erez Imaging Server is used for the presentation of objects. 


\section{CONCLUSION}

Planning stage and also research on behaviour and needs of users were very important parts of the project. They allowed to define the functionality of the application. The element that ensures effectiveness of the works is the implementation of modern information technology. Also truly important is to ensure enough time for testing the final version of the application before its implementation. Applying the international standards of monument descriptions is the only way to develop, promote, exchange and enlarge the database. The key problem in developing such initiatives is unwillingness to share the resources (also the digital copies) and low level of digitalization of Polish archives. Close cooperation between the experts from different institutions was one of the most important factor that enabled the realisation of the project. It ensured an interdisciplinary approach to the problem and professionalism in every stage. The authors have not known other (the same or similar) solutions. No information on similar solution has been found in the specialist literature. The application developed by the authors is the only one that presents this topic in such complex way.

\section{REFERENCES}

[1] Meissner, D., (ed.): RLG Best Practice Guidelines for Encoded Archival Description (translation: H. Wajs, AGAD), Research Libraries Group, California, USA, 2002,

[2] Moscicka, A., Marzec, M.: Methodology for mapping movable heritage - assumptions of the project (in Polish),

Conference "Digital meeting with monuments - the status and development prospects of contemporary methodology", Wroclaw, Poland, 19 September 2008,

[3] Moscicka, A., Marzec, M.,: The advantages of geovisualization (in Polish), NASK Review 3,Warsaw, Poland, 2008

[4] Ordinance of the Minister of Internal Affairs and Administration: Structure of the necessary elements of electronic documents (in Polish), Journal of Laws, No 2006, pos. 1517, Warsaw, Poland, 30 October 2006

[5] http://www.dlib.indiana.edu/services/metadata/activities/EADManual.pdf

[6] Wajs, H.: EAD - basic information (in Polish), 2000, http://www.agad.archiwa.gov.pl/ead/ead.ppt

[7] Wajs, H.: Polish road to the standardization of archival description (in Polish), Digital archives, E. Rosowska (ed.), Warsaw, Poland, 2003

[8] Wajs, H., Marzec, M.: Dynasty on the Internet (in Polish), NASK Review 2/2009, Warsaw, Poland 